\title{
REGULAÇÃO DE ORGANISMOS GENETICAMENTE MODIFICADOS DE USO AGRÍCOLA NO BRASIL E SUA RELAÇÃO COM OS MODELOS NORMATIVOS EUROPEU E ESTADUNIDENSE
}

\author{
Regulation of genetically modified organisms for \\ agricultural use in Brazil and its relationship with the \\ United States and European regulatory models
}

\author{
Patrícia Rossi Moriconi* \\ Paloma de Oliveira Tonietti** \\ Luisa Zanolli Moreno*** \\ Glavur Rogério Matté
}

\section{RESUMO}

A biotecnologia avançou consideravelmente nos séculos $X X$ e $X X I$, de tal forma que, atualmente, 29 países são responsáveis pela produção de 160 milhões de hectares de organismos geneticamente modificados (OGMs). Esse desenvolvimento científico, tecnológico e produtivo requer medidas de monitoramento e controle para impedir grandes e futuros danos da introdução desses produtos no meio ambiente e no mercado. O presente trabalho teve como objetivo apresentar o cenário brasileiro dos alimentos geneticamente modificados e a evolução do corpo legislativo nacional relativo a eles, analisando-o com base nas políticas internacionais de produção e comércio de transgênicos. Para tanto, foi realizado um levantamento no que tange à legislação e literatura, reportadas até o momento, sobre a evolução do cenário dos OGMs de origem vegetal no Brasil e no mundo,

* Mestranda, Faculdade de Medicina Veterinária e Zootecnia, Universidade de São Paulo. São Paulo/SP - Brasil. E-mail: patrícia.moriconi@usp.br

** Mestranda, Faculdade de Medicina Veterinária e Zootecnia, Universidade de São Paulo. São Paulo/SP - Brasil. E-mail: palomatonietti@usp.br

*** Mestranda, Faculdade de Saúde Pública, Universidade de São Paulo. São Paulo/SP - Brasil. E-mail: luisa.moreno@usp.br

**** Doutor em Saúde Pública, Faculdade de Saúde Pública, Universidade de São Paulo. Professor Associado, Faculdade de Saúde Pública, Universidade de São Paulo. São Paulo/SP - Brasil. E-mail: grmatte@usp.br

Artigo recebido em: 29/10/2012. Revisado em: 19/02/2013. Aprovado em: 01/03/2013. 
de 2007 a 2011, relacionando os dados obtidos com os modelos normativos europeu e estadunidense. As ações de vigilância sanitária no campo dos organismos geneticamente modificados são fundamentalmente de controle, monitoramento e fiscalização das etapas de desenvolvimento, plantio e comércio dos produtos transgênicos. A legislação brasileira segue os padrões internacionais de boas condutas relacionadas aos organismos geneticamente modificados, com normativas protetoras e com agências fiscalizadoras das atividades com esses produtos. No entanto, encontra-se em meio à dualidade das divergentes condutas europeia e americana, nas quais prevalece, atualmente, um posicionamento liberal.

Palavras-chave: Biossegurança; Legislação Sanitária; Organismos Geneticamente Modificados (OGMs); Transgênicos; Vigilância Sanitária.

\begin{abstract}
Biotechnology has advanced much in the XX and XXI century, so that currently 29 countries are responsible for the production of 160 million hectares of genetically modified organisms (GMO). This scientific, technological and productive development requires monitoring and control measures to prevent major and future damage from the introduction of these products on the environment and the market. The aim of this paper was to present the Brazilian scenario of genetically modified organisms and the development of the national legislative body relative to them, analyzing it based on the international politics of production and trade of transgenics. It was studied the legislation and literature, reported to date, about the development of genetically modified organisms' framework in Brazil and in the world, from 2007 to 2011, comparing these data with the United States and European normative models. The health surveillance activities in the field of genetically modified organisms are fundamentally: control, monitoring and supervision of the stages of development, cultivation and trade of transgenic products. Brazilian legislation follows international standards of good conduct relating to genetically modified organisms, with protective normative and regulatory agencies of the activities with these products. However, Brazilian rules is among the duality of the divergent European and American conducts in which prevails, today, a liberal position.
\end{abstract}

Keywords: iosecurity; Genetically Modified Organisms (GMO); Sanitary Legislation; Sanitary Surveillance; Transgenic.

\title{
Introdução
}

A vigilância sanitária é "um conjunto de ações capaz de eliminar, diminuir ou prevenir riscos à saúde e de intervir nos problemas sanitários decorrentes do 
meio ambiente, da produção e circulação de bens e da prestação de serviços de interesse à saúde". (1) Essa definição introduz o conceito de risco e confere o campo de abrangência vasto e ilimitado de ações que se inserem nesse contexto, podendo intervir em todos os aspectos que possam afetar a saúde dos cidadãos. ${ }^{(2)}$ No campo dos organismos geneticamente modificados (OGMs), as ações de vigilância sanitária abrangem três dimensões: o trabalhador; a saúde humana e animal; e o meio ambiente. No entanto, suas ações são fundamentalmente de controle, monitoramento e fiscalização das etapas de desenvolvimento, plantio e comércio dos OGMs.

Segundo Rodrigues, ${ }^{(3)}$ a combinação do genoma de plantas, animais e micro-organismos, ou seja, genes de organismos distintos filogeneticamente, surgiu dentro do ramo da biotecnologia. Esta, em seu sentido clássico, refere-se a qualquer técnica que usa organismos vivos (ou parte deles) para elaborar ou modificar produtos no sentido de melhorá-los ou desenvolver uma nova substância para uso específico. Com base nessa definição, a utilização do lêvedo para produzir cerveja, a transformação do leite em iogurtes e queijos e o processo de fermentação para fabricar vinho eram considerados eventos biotecnológicos. Contudo, o advento da engenharia genética, na década de 1970, permitiu o desenvolvimento da biotecnologia moderna, que é fundamentada na utilização de métodos que modificam o material genético das células vivas para produção de novas substâncias ou o desempenho de novas funções. Segundo a Monsanto do Brasil, ${ }^{(4)}$ a designação de transgênicos se restringe ao ato de transferir ou inserir apenas o gene desejado do organismo doador na nova variedade a ser melhorada ou desenvolvida.

No contexto do século XXI, os OGMs ganham cada vez mais importância econômica pelo aumento da produção e pela evolução técnico-científica que proporcionam. No entanto, apesar dos benefícios, até o momento, não se sabe ao certo quais serão os efeitos da liberação desses organismos no meio ambiente. Uma das preocupações concernentes a esse aspecto é de que os OGMs possam se combinar com outras plantas da mesma espécie, dando origem a gerações cujas características genéticas são imprevisíveis, mas que podem ter alguma vantagem competitiva no ambiente em que vivem, transformando tal espécie numa praga ambiental. Atualmente, existem duas tendências políticas mundiais em relação à produção de OGM: uma extremamente liberal, que atribui, à empresa responsável pelo produto, danos

\footnotetext{
${ }^{1}$ BRASIL. Lei Federal n 8.080, de 19 de setembro de 1990. "Dispõe sobre as condições para a promoção, proteção e recuperação da saúde, a organização e funcionamento dos serviços correspondentes e dá outras providências". Diário Oficial da União, 1990; 20 set.

2 EDUARDO, Maria Bernadete de Paula; MIRANDA, Isaura Cristina Soares de. Programas de Vigilância Sanitária. In: Noções básicas sobre vigilância sanitária. São Paulo: Fundação Peirópolis, 1998. v. 8, p. 9.

${ }^{3}$ RODRIGUES, Regina S. Minazzi. Alimentos transgênicos. In: Higiene e vigilância sanitária de alimentos. 2. ed. São Paulo: Varela Ed.; Livr., 2003. p. 541-573.

${ }^{4}$ MONSANTO do Brasil Ltda. Biotecnologia: soluções para o mundo de amanhã. nov. 1997.
} 
posteriores ao plantio, representada pelos Estados Unidos da América, e uma política conservadora, fundamentada no princípio da precaução e em análises de riscos e impactos ambientais, que tem como principal representante os países da União Europeia. ${ }^{(5)}$ Essas políticas ainda causam conflitos, sejam estes de fundo econômico, sejam mesmo de fundo ambiental, entre os países produtores e comerciantes de OGMs, e mobilizam agências internacionais relacionadas ao comércio, saúde e proteção ambiental.

O objetivo do presente trabalho é apresentar a situação dos alimentos geneticamente modificados no Brasil, a evolução do corpo legislativo nacional relativo a estes e, por fim, analisá-lo com base nas políticas mundiais de produção e comércio de OGMs. Para tanto, foi realizado um levantamento nas legislações e na literatura publicadas até o momento sobre a evolução do cenário dos OGMs de origem vegetal no Brasil e no mundo de 2007 a 2011, relacionando os dados obtidos com os modelos normativos europeu e estadunidense.

\section{Evolução do cenário dos organismos geneticamente modificados de origem vegetal no Brasil e no mundo de 2007 a 2011}

De acordo com James, ${ }^{(6)}$ o início da comercialização dos OGMs data de 1996. Deste ano até 2007, houve um aumento de 67 vezes na produção de OGMs, evidenciando a rápida adoção da biotecnologia agrícola. Esses primeiros quinze anos mostraram que as lavouras de OGMs ofereceram benefícios tanto para os países industrializados quanto para os emergentes, observando-se o crescimento do plantio desse tipo de produto a cada ano. Em 2011, pelo $15^{\circ}$ ano consecutivo, a área global de lavouras de OGMs continuou a aumentar, alcançando 160 milhões de hectares no âmbito mundial. Nesse ano, o número de países que adotam essa biotecnologia atingiu um total de 29 , abrangendo 19 países em desenvolvimento e 10 industrializados, sendo os dez primeiros, em ordem de hectares cultivados: Estados Unidos da América (EUA), Brasil, Argentina, Índia, Canadá, China, Paraguai, Paquistão, África do Sul e Uruguai. Em 2011, os EUA eram o país que apresentava maior adesão aos OGMs, totalizando uma área de 69 milhões de hectares plantados. Brasil e Argentina são os países com a segunda e terceira maiores áreas plantadas de OGMs; o primeiro

\footnotetext{
${ }^{5}$ SUZUKI, Jorge Brunetti. OGM: aspectos polêmicos e a nova lei de biossegurança. Jus Navigandi, Teresina, n. 997. Disponível em: <http://jus.uol.com.br/revista/texto/8148/ogm-aspectos-polemicose-a-nova-lei-de-biosseguranca>. Acesso em: 28 abr. 2011.

6 JAMES, Clive. Situação Global das Culturas Biotecnológicas/ GM Comercializadas: 2008. In: RELATÓRIO do Serviço Internacional para a Aquisição de Aplicações de Agrobiotecnologias (ISAAA), 2008. Sumário Executivo, n. 39, 31p. Disponível em: <http://www.isaaa.org/resources/ publicacations/briefs/39/default.html>. Acesso em: 21 abr. 2011.
} 
totaliza cerca de 30 milhões de hectares plantados e o segundo, 23,7 milhões de hectares plantados. ${ }^{(7)}$ Até 2008, o Brasil ocupava a posição da Argentina, ocorrendo a inversão em 2009.

Durante o período de 1996 a 2011, a proporção da área global de lavouras geneticamente modificadas cultivadas por países em desenvolvimento aumentou de forma consistente. Em 2011, aproximadamente $50 \%$ da área agrícola mundial cultivada com biotecnologia localizava-se nessas nações e, pela primeira vez, espera-se que elas ultrapassem os países industrializados em 2012, o que é contrário à previsão de críticos, os quais afirmavam que o uso dessa tecnologia não seria adotado por países em desenvolvimento. Além disso, nesse ano, a taxa de crescimento do plantio de OGMs foi duas vezes maior nesses países do que nos industrializados $-11 \%$ contra $5 \%$. $^{(8)}$

Atualmente, os cinco principais países em desenvolvimento comprometidos com os OGMs de origem vegetal são Brasil, Índia, China, Argentina e África do Sul, todos localizados em continentes do hemisfério Sul. É importante ressaltar também que, do total global de agricultores que adotaram a biotecnologia, $90 \%$ são pequenos agricultores, dos quais a maioria adotou o cultivo do algodão transgênico resistente a insetos (algodão Bt), principalmente na China e na Índia. ${ }^{\left({ }^{9}\right)}$

O Brasil ocupa o segundo lugar em área de OGMs plantada, perdendo apenas para os EUA, e tem emergido como um líder global na área de OGM. Pelo terceiro ano consecutivo, o Brasil se apresenta como a força motriz do crescimento global, aumentando a sua área mais do que qualquer outro país no mundo. Em 2011, essa área cresceu 4,9 milhões de hectares, o que equivale a um incremento de $20 \%$ ao ano. Segundo James, ${ }^{(10)}$ o motivo desse grande crescimento refere-se ao fato do rápido sistema de aprovação desses cultivares, o que permitiu ao Brasil aprovar oito eventos em 2010 e, até outubro de 2011, mais seis eventos.

Em 2008, Costa Rica e Burkina Faso adotaram a biotecnologia agrícola, completando um total de 25 países que produzem OGMs. Esse quadro se manteve em 2009, e no ano de 2010 ocorreu a adesão de mais quatro países: Paquistão, Myanmar, Suécia e Alemanha. Os dois primeiros países adotaram o cultivo de algodão transgênico, enquanto os dois últimos aderiram ao plantio de batata

\footnotetext{
7 JAMES, Clive. Situação Global das Lavouras GM Comercializadas: 2011. In: Relatório do Serviço Internacional para a Aquisição de Aplicações de Agrobiotecnologias (ISAAA), 2011: Sumário Executivo, n. 43, 36p. Disponível em: <http://www.isaaa.org/resources/publicacations/briefs/43/ default.html>. Acesso em: 23 ago. 2011.

8 Id. Ibid., p.7.

9 JAMES, Clive. Situação Global das Culturas Biotecnológicas/ GM Comercializadas: 2009. In: RELATÓRIO do Serviço Internacional para a Aquisição de Aplicações de Agrobiotecnologias (ISAAA), 2009. Sumário Executivo, n. 41, 50p. Disponível em: <http://www.isaaa.org/resources/ publicacations/briefs/ 41/default.html>. Acesso em: 21 abr. 2011.

${ }^{10}$ Id. Ibid., p. 9.
} 
transgênica. ${ }^{(11)}$ O quadro manteve-se estável em 2011, não havendo adesão de nenhum novo país.

Em novembro de 2009, ocorreram duas aprovações históricas e com grandes implicações na adoção de culturas biotecnológicas em todo o mundo. Tais aprovações incluíram o arroz resistente a insetos (arroz Bt) e o milho biotecnológico com fitase, ambos desenvolvidos e patenteados na China exclusivamente com recursos do setor público. A aprovação desses dois alimentos básicos, considerados como as principais culturas utilizadas na alimentação humana e animal, poderá facilitar e apressar a aceitação dos alimentos biotecnológicos e, também, poderá mudar a dinâmica do comércio mundial de alimentos. ${ }^{(12)}$

A primeira aprovação para a liberação comercial de um organismo geneticamente modificado de origem vegetal ocorreu, no Brasil, em 1998. Tal produto foi a soja Roundup Ready, tolerante ao herbicida glifosato. Após esse ano, somente em 2005 foi obtida nova liberação comercial para o algodão MON 531 - BOLLGARD I, resistente a insetos da ordem Lepidoptera. A partir de 2007 ocorreu um número maior de aprovações comerciais de OGMs de origem vegetal, sendo liberadas três estirpes de milho geneticamente modificado. Em 2008 foram aprovados cinco eventos agronômicos, sendo três cultivares de milho e dois de algodão. No ano seguinte houve a aprovação de sete cultivares geneticamente modificados de soja, milho e algodão. Em 2010, novos produtos geneticamente modificados, das mesmas variedades anteriores, foram liberados para o comércio. Em fevereiro de 2011 já havia sido aprovado um evento agronômico - o algodão GHB $119 X$ T304-40. Dentre os transgênicos já liberados comercialmente no Brasil prevalecem os cultivares de soja, algodão e milho tolerantes a herbicidas e resistentes a insetos. Esses produtos, além de serem utilizados para consumo interno no país, são os responsáveis pela posição do Brasil como um dos principais exportadores de OGMs do mundo. ${ }^{(13)}$ Além disso, em 2011, a Empresa Brasileira de Pesquisa Agropecuária (Embrapa) obteve a aprovação para comercializar uma variedade de feijão resistente a vírus, evento considerado importantíssimo por Anderson Galvão, sócio-diretor da Céleres Consultoria, uma vez que é o primeiro produto transgênico a chegar diretamente à mesa do consumidor, sem nenhum processamento, diferentemente da soja e do milho.(14),(15)

\section{Legislação internacional sobre biossegurança}

\footnotetext{
${ }^{11}$ JAMES, Clive. Situação Global das Culturas Biotecnológicas/ GM Comercializadas: 2009, cit., p. 9. ${ }^{12}$ Id. Ibid., p. 9.

${ }^{13}$ CTNBIO, 2011. Eventos aprovados pela CTNbio. Disponível em: <http://www.cib.org.br/ biotecnologia/regulamentacao/ctnbio/eventos-provados>. Acesso em: 21 abr. 2011.

${ }^{14}$ Id. Ibid., p. 7.

${ }^{15}$ MILÉRIO, Júnior. Brasil bate recorde em biotecnologia agrícola em 2011: área plantada com transgênicos subiu $20 \%$ e País aprovou primeira semente nacional. Sou Agro, 7 fev. 2012. Disponível em: <http:// www.souagro.com.br/brasil-bate-recorde-em-biotecnologia-agricola>. Acesso em: 23 ago., 2012.
} 
No cenário internacional, há duas vertentes a respeito da regulamentação de OGMs: a americana e a europeia. ${ }^{(16)}$

Os EUA apresentam uma das legislações mais complexas sobre biossegurança. Várias agências e órgãos estatais estão envolvidos com os transgênicos. No entanto, apenas apresentam uma divisão de tarefas entre os entes deliberativos e fiscalizadores e não defendem uma única posição decisória quanto ao tema. ${ }^{(17)} \mathrm{O}$ controle sobre as liberações de produtos geneticamente modificados no meio ambiente é caracteristicamente brando, bem como o alto investimento nas áreas de pesquisa. A política americana é fundamentada na verificação a posteriori, mantendo uma postura liberal para o plantio de OGMs sem requisitos de estudos prévios de impacto ambiental e, se necessário, responsabilizando a empresa desenvolvedora do produto por danos posteriores ao plantio. ${ }^{(18)}$ Além disso, esse país se utiliza do princípio da equivalência substancial para permitir a liberação do OGM em seu mercado. ${ }^{(19)}$ Esse princípio foi formulado em 1993 pela Organização para Cooperação e Desenvolvimento Econômico (OCDE) e se baseia na comparação entre os alimentos geneticamente modificados com os alimentos convencionais relacionados. ${ }^{(20)}$ É a fidelidade a esse princípio que faz com que as normas americanas não exijam a segregação e a rotulagem de alimentos geneticamente modificados. ${ }^{(21)}$ No entanto, apesar da praticidade desse princípio, ao longo do tempo, foram levantadas críticas, ${ }^{(22)}$ que foram responsáveis por uma revisão nas bases do princípio e suas limitações, resultando em novas recomendações a este princípio. ${ }^{(23)}$ Desse modo, entende-se que o fato de um alimento geneticamente modificado ser equivalente ao análogo convencional não implica sua segurança ambiental e à saúde humana, sendo o inverso também verdadeiro. ${ }^{(24)}$ Segundo Camara et al.. ${ }^{(25)}$ o conceito de equivalência substancial é considerado pseudocientífico por Millstone, Brunner

${ }^{16}$ LEITE, Marcelo. EUA podem rever liberalismo transgênico. Folha de S. Paulo, São Paulo, 12 jan. 2011. Disponível em: <http://www.agrosoft.org.br/agropag/217104.htm>. Acesso em: 12 maio 2011.

${ }^{17}$ LEITE, Marcelo. op. cit., p. 5.

${ }^{18}$ LAJOLO, Franco Maria; NUTTI, Marília Regini. Transgênicos: bases científicas da sua segurança. São Paulo: Sociedade Brasileira de Alimentação e Nutrição, 2003.

${ }^{19}$ FARIA, Carmen Rachel S. M. A polêmica dos transgênicos: aspectos técnicos, legais e econômicos. Senado Federal - Consultoria Legislativa, Brasília, 31 p. 2005. Disponível em: <http://www.senado.gov. $\mathrm{br} /$ senado/conleg/artigos/ politicasocial/ApolemicadosTransgenicos.pdf>. Acesso em: 03 abr. 2011.

${ }^{20}$ Id. Ibid., p. 18.

${ }^{21}$ KUIPER, Harry A.; KLETER, Gijs A.; NOTEBORN, Hub P. J. M.; KOK, Esther J. Assessment of the food safety issues related to genetically modified foods. The Plant Journal, London, v.27, n.6, p.503528, 2001.

${ }^{22}$ MILLSTONE, Erik; BRUNNER, Eric; MAYERS, Sue. Beyond substancial equivalence. Nature, v. 401, p.525-526, 1999.

${ }^{23} \mathrm{FAO} / \mathrm{WHO}$. Evaluation of allergenicity modified foods: report of a Joint FAO/WHO Expert Consultation on Allergenicity of Foods Derived from Biotecnology. 2000. Disponível em: <http:// www.fao.org/docrep/007/ y0820e/y0820e00.htm>. Acesso em: 8 ago. 2011.

${ }^{24}$ Id. Ibid., p. 21.

${ }^{25}$ CAMARA, Maria Clara Coelho; MARINHO, Carmem L. C.; GUILAM, Maria Cristina Rodrigues; NODARI, Rubens Onofre. Transgênicos: avaliação da possível (in)segurança alimentar através da produção científica. História, Ciências, Saúde-Manguinhos, Rio de Janeiro, v. 16, n. 3, p. 669-681, 2009. 
e Mayers, ${ }^{(26)}$ e foi adotado com objetivos políticos e comerciais favoráveis às empresas produtoras de OGMs com o intuito de tranquilizar a população.

A legislação europeia, por sua vez, é fundamentada no princípio da precaução, que deve ser expresso em suas normativas, assim como incluindo a necessidade do Estudo Prévio de Impacto Ambiental (EIA). De forma geral, a União Europeia estabelece as normativas e os princípios de base para o tema e cada país-membro é responsável pela definição de uma autoridade competente para monitoramento, fiscalização e domínio de informações acerca de acidentes e resoluções a respeito de OGMs. A União Europeia reconhece a necessidade de proteger o meio ambiente e que o acesso à informação e à participação pública no processo de tomada de decisão contribuem para a conscientização em assuntos ambientais, fornecendo ao público a oportunidade de expressar suas preocupações e, consequentemente, a ciência das autoridades públicas. ${ }^{(27)}$

O processo de autorização de um novo OGM, segundo as normativas europeias, consiste em três fases: submissão de projeto, avaliação de segurança e decisão final para liberação do produto geneticamente modificado no ambiente e registro. O projeto deve conter toda identificação do OGM e seus componentes, estudos de impacto ambiental, análise de equivalência ao produto "convencional", sugestões para rótulo e proposta de monitoramento pós-liberação comercial. O projeto é encaminhado para a Autoridade Europeia de Segurança Alimentar (European Food Safety Authority - [EFSA]) para análise científica da proposta, a qual, após um período máximo de seis meses, conduz o projeto e sua decisão à Comissão Europeia e aos estados-membro, que emitem a decisão final de autorização para liberação ambiental e comercial do novo OGM. ${ }^{(28)}$

\section{Legislação brasileira relativa aos produtos geneticamente modificados}

A legislação brasileira relativa aos OGMs é fundamentada no princípio da precaução, que tem por objetivo prevenir ou oferecer margem de segurança a uma situação de perigo potencialmente possível. Isso significa que o perigo existe, mas que não se sabe ao certo se irá acontecer. Considerando que o risco é a probabilidade da ocorrência desse perigo, pode-se dizer que o risco reside no fato de que, ao se construir um OGM, podem acontecer efeitos intencionais (relacionados à característica do gene introduzido) e efeitos não intencionais (que podem ser previsíveis ou não). Mudanças morfológicas são detectáveis com facilidade, ao passo que

\footnotetext{
${ }^{26}$ CAMARA, Maria Clara Coelho; MARINHO, Carmem L. C.; GUILAM, Maria Cristina Rodrigues; NODARI, Rubens Onofre. op. cit., p. 18.

${ }^{27}$ GMO-Compass. The European Regulatory System. Genetic Engineering, Plants, and Food. 2, Jun., 2006. Disponível em: <http://www.gmo-compass.org/eng/regulation/regulatory_process/156. european_regulatory_system_genetic_engineering.html >. Acesso em: 11 maio 2011.

${ }^{28} \mathrm{GMO}$-Compass. EU: GMO Authorisation Procedures. 10 Jan. 2006. Disponível em: <http://www. gmocompass.org/eng/regulation/regulatory_process/157.eu_gmo_authorisation_procedures. html>. Acesso em: 12 maio 2011.
} 
mudanças genômicas não são prontamente visíveis, e podem causar mudanças importantes na expressão de enzimas e em diversas vias metabólicas através de mecanismos ainda não totalmente conhecidos. ${ }^{(29)}$ Portanto, nesse contexto de falta de conhecimento, a inserção dos organismos geneticamente modificados deve ser considerada como um risco desconhecido e ainda não mensurado, ${ }^{(30)}$ que necessita de avaliação prévia e detalhada antes de se liberarem esses produtos no meio ambiente e, posteriormente, no comércio. Com o objetivo de se conhecer o efeito dos alimentos geneticamente modificados no organismo animal, trabalhos têm sido desenvolvidos. Em um deles, realizado por Pusztai, ${ }^{(31)}$ ratos alimentados com batatas transgênicas tiveram alterações no sistema imunológico e também no desenvolvimento de vários órgãos. Apesar de outros trabalhos semelhantes não terem chegado a esses resultados, mostra-se a necessidade da contínua investigação dos efeitos dos transgênicos nos organismos animais.

O princípio da precaução foi introduzido às normativas brasileiras com a formulação da Constituição Federal de 1988, que apresentou as primeiras normas voltadas especificamente para a defesa do meio ambiente. Essa abordagem transmite à sociedade e ao Poder Público o dever de defender e preservar o meio ambiente de forma a evitar que prevaleça apenas o intuito corretivo, que também existe na forma de sanções e punições para os causadores dos danos. ${ }^{(32)}$ Com isso, são introduzidos os preceitos da legislação de OGM e o conceito de estudo prévio de impacto ambiental.

As normativas de produtos geneticamente modificados se iniciaram no país com a Lei $n^{\circ} 8.974$, em 1995, denominada Lei de Biossegurança. Esta apresentava as normas de segurança e os mecanismos para fiscalização das técnicas de engenharia genética no desenvolvimento, cultivo, comercialização, consumo, liberação e descarte de OGMs. A lei dispõe sobre a criação da Comissão Técnica Nacional de Biossegurança (CTNBio), vinculada ao Ministério da Ciência e Tecnologia, com o objetivo de propor a Política Nacional de Biossegurança e, a partir desta, monitorar o desenvolvimento técnico e científico dos OGMs, estabelecendo procedimentos padrões e regulamentos para todas as atividades que envolvam produtos geneticamente modificados, visando assegurar a proteção do meio ambiente e do consumidor. A CTNBio é composta por especialistas de biotecnologia humana, animal, vegetal e ambiental, representantes dos ministérios, representante de órgão de defesa do consumidor e de proteção à saúde do trabalhador, dentre outros. ${ }^{(33)}$

\footnotetext{
${ }^{29}$ CAMARA, Maria Clara Coelho; MARINHO, Carmem L. C.; GUILAM, Maria Cristina Rodrigues; NODARI, Rubens Onofre. op. cit., p. 18.

${ }^{30}$ GMO-Compass. EU: GMO Authorisation Procedures. 10 Jan. 2006, cit., p. 5.

${ }^{31}$ PUSZTAI, ÀRPÁD. Pusztai's submission on the health impact of GM crops - Evidence to the Health committee of the Scottish Parliament. 4 dez. 2002. Disponível em: <http://ngin.tripod.com/041202e. htm>. Acesso em: 12 ago. 2011.

${ }^{32}$ Id. Ibid., p. 5.

${ }^{33}$ AMÂNCIO, Mônica Cibele; SAMPAIO, Maria José. Legislação de biossegurança no Brasil: cenário atual. Conselho de Informações de Biotecnologia, 2004. Disponível em: <http://cib.org.br/wp-content/ uploads/2011/10/legislacao_biosseguranca_brasil_monica_cibele.pdf>. Acesso em: 10 maio 2011.
} 
O Decreto $n^{\circ} 1.752,{ }^{(34)}$ de 1995 , estabelece de fato a criação da CTNBio, constituindo-a como um órgão multidisciplinar para prestar apoio técnico e assessorar o governo federal com a Política Nacional de Biossegurança, no tocante aos OGMs. Apesar de a CTNBio constituir a instância máxima no contexto dos OGMs, cabe aos ministérios da Saúde (MS), da Agricultura, Pecuária e Abastecimento (MAPA) e do Meio Ambiente (MMA) fiscalizar e monitorar as atividades relacionadas aos OGMs, emitir certificados de comercialização ou liberação, autorizar importações e encaminhar as informações sobre as atividades exercidas à CTNBio. ${ }^{(35)}$ No entanto, essa Comissão ainda é controversa com relação a exigir o EIA e Relatório de Impacto ao Meio Ambiente (RIMA) apenas como documentação adicional para a elaboração do parecer técnico conclusivo sobre o produto geneticamente modificado e a atividade a ele relacionada. Esse fato fere o requisito constitucional do estudo do impacto ambiental fundamentado no Princípio da Precaução.

Até 2004, o MAPA demonstrava completa negligência pela fiscalização do plantio de transgênicos no país. A partir de 2006, esse serviço passou a ser realizado pelo Programa de Fiscalização de Atividades com OGM (FISCORGEN), criado pelo ministério para se adequar à Lei de Biossegurança, conjuntamente com a Coordenação Específica de Biossegurança de OGM na Secretaria de Defesa Agropecuária (CBIO/DAS) e outros órgãos que culminaram na edição de normas complementares para regulamentar a atuação do MAPA. ${ }^{(36)}$

Em 1997, a Lei de Proteção aos Cultivares (Lei n 9.456$)^{(37)}$ foi aprovada, permitindo que o responsável pelo desenvolvimento de um novo cultivar obtido através da modificação genética registre a variedade desenvolvida e obtenha sua propriedade intelectual, podendo cobrar royalties daqueles que a cultivarem. Essa lei foi necessária para complementar a Lei de Propriedade Industrial,(38) que incluía o

\footnotetext{
${ }^{34}$ BRASIL. Decreto $n^{\circ} 1752$, de 20 de dezembro de 1995. "Regulamenta e Lei n 8974, de 5 de janeiro de 1995 dispõe sobre a vinculação, competência e composição da Comissão Técnica Nacional de Biossegurança- CTNBio, e dá outras providência". Diário oficial da União, 21 dez. 1995.

${ }^{35}$ BRASIL. Lei $\mathrm{n}^{\circ} 11.105$, de 24 de março de 2005. "Regulamenta os incisos II, IV e V do parágrafo $1^{\circ}$ do art. 225 da Constituição Federal, estabelece normas de segurança e mecanismos de fiscalização de atividades que envolvam organismos geneticamente modificados- OGM e seus derivados, cria o Conselho Nacional de Biossegurança- CNBS, reestrutura a Comissão Técnica Nacional de Biossegurança - CTNBio, dispõe sobre a Política Nacional de Biossegurança- PNB, revoga a Lei $n^{\circ} 8974$, de 5 de janeiro de 1995, e a Medida Provisória $n^{\circ} 2191-9$, de 23 de agosto de 2001 , e os arts. $5^{\circ}, 6^{\circ}, 7^{\circ}, 8^{\circ}, 9^{\circ}, 10$ e 16 da Lei no 10.814 , de 15 de dezembro de 2003 , e dá outras providências. Diário Oficial da União, 28 mar. 2005.

${ }^{36}$ COELHO, Marcus Vinícius S. Medidas e ações envolvendo OGM e seus derivados no âmbito das competências do MAPA. Reunião GT - Transgênico da $3^{a}$ e $4^{a}$ CCR. SDA/MAPA. Brasília, 17 de setembro de 2007.

${ }^{37}$ BRASIL. Lei n 9.456, de 25 de abril de 1997. "Institui a Lei de Proteção de Cultivares e dá outras providências.". Disponível em: <http://www.planalto.gov.br/ccivil_03/leis/L9456.htm>. Acesso em: 19 jan. 2014.

${ }^{38}$ BRASIL. Lei n 9.279, de 14 de maio de 1996. "Regula direitos e obrigações relativos à propriedade industrial”. Disponível em: <http://www.planalto.gov.br/ccivil_03/leis//9279.htm>. Acesso em: 19 jan. 2014.
} 
domínio sobre seres vivos, de tal forma que não permitia o registro e a cobrança sobre a aplicação da tecnologia desenvolvida. ${ }^{(39)}$ Já em 2002, o Conselho Nacional do Meio Ambiente (Conama) liberou a Resolução $n^{\circ} 305,{ }^{(40)}$ que dispõe sobre o Licenciamento Ambiental para pesquisa e comercialização de OGMs, além da necessidade do EIA e do RIMA para as atividades com produtos geneticamente modificados e seus derivados. Essa resolução regulamenta, especificamente no caso de OGMs, o instrumento "licenciamento ambiental de atividades potencial ou efetivamente poluidoras" da Política Nacional de Meio Ambiente (Lei $\left.n^{\circ} 6.938 / 81\right),{ }^{(41)}$ fundamentado nas Resoluções $n^{\circ} 237 / 97^{(42)}$ e $001 / 86,{ }^{(43)}$ que estabelecem as diretrizes gerais do licenciamento ambiental e do EIA. ${ }^{(44)}$

Em 2002, também foi liberado o Decreto $n^{\circ} 4.074,{ }^{(45)}$ que complementa a legislação de produtos agrotóxicos (Lei $\left.n^{\circ} 7.802 / 89\right)^{(46)}$ em relação aos biopesticidas, incluindo os OGMs dotados dessa característica. Dessa forma, são de responsabilidade da Agência Nacional de Vigilância Sanitária (Anvisa), do MAPA e do MMA, a análise e o monitoramento dos OGMs de ação biopesticida, sendo necessário emitir Registro Especial Temporário (RET/OGM) para cada produto em cada fase de seu desenvolvimento (pesquisa laboratorial e em campo). Os demais requerimentos para desenvolvimento de pesquisa com OGMs, como a emissão do Certificado de Qualidade em Biossegurança (CQB), a instalação da Comissão Interna de Biossegurança (CIBio), além das normas para liberação

\footnotetext{
${ }^{39}$ BRASIL. Lei ${ }^{\circ}$ 9.279, de 14 de maio de 1996, cit.

${ }^{40}$ BRASIL. Ministério do Meio Ambiente. Resolução $n^{\circ} 305$, de 12 de junho de 2002. "Dispõe sobre Licenciamento Ambiental, Estudo de Impacto Ambiental e Relatório de Impacto no Meio Ambiente de atividades e empreendimentos com Organismos Geneticamente Modificados e seus derivados.". Disponível em: <http://www.mma.gov.br/port/conama/res/res02/res30502.html>. Acesso em: 19 jan. 2014.

${ }^{41}$ BRASIL. Lei n ${ }^{\circ} 6.938$, de 31 de agosto de 1981. "Dispõe sobre a Política Nacional do Meio Ambiente, seus fins e mecanismos de formulação e aplicação, e dá outras providências.". Disponível em: <http://www.planalto.gov.br/ccivil_03/leis/L6938compilada.htm>. Acesso em: 19 jan. 2014.

${ }^{42}$ BRASIL. Ministério do Meio Ambiente. Resolução $n^{\circ}$ 237, de 19 de dezembro de 1997. Disponível em: <http://www.mma.gov.br/port/conama/res/res97/res23797.html>. Acesso em: 19 jan. 2014.

${ }^{43}$ BRASIL. Ministério do Meio Ambiente. Resolução $n^{\circ} 001$, de 23 de janeiro de 1986. Disponível em: <http://www.mma.gov.br/port/conama/res/res86/res0186.html>. Acesso em: 19 jan. 2014.

${ }^{44}$ COSTA, Joselaine da ; KIST, Ataídes.; MATTÉ, Glavur Rogério; MATTÉ, Maria Helena. Alimentos geneticamente modificados: aspectos regulatórios e de saúde pública. Revista de Direito Sanitário, São Paulo, v. 4, n. 3, p. 107-125, 2003.

${ }^{45}$ BRASIL. Decreto $n^{\circ} 4.074$, de 4 de janeiro de 2002. "Regulamenta a Lei no 7.802 , de 11 de julho de 1989, que dispõe sobre a pesquisa, a experimentação, a produção, a embalagem e rotulagem, o transporte, o armazenamento, a comercialização, a propaganda comercial, a utilização, a importação, a exportação, o destino final dos resíduos e embalagens, o registro, a classificação, o controle, a inspeção e a fiscalização de agrotóxicos, seus componentes e afins, e dá outras providências.". Disponível em: <http://www.planalto.gov.br/ccivil_03/decreto/2002/d4074.htm>. Acesso em: 19 jan. 2014.

${ }^{46}$ BRASIL. Lei $n^{\circ} 7.802$, de 11 de julho de 1989. "Dispõe sobre a pesquisa, a experimentação, a produção, a embalagem e rotulagem, o transporte, o armazenamento, a comercialização, a propaganda comercial, a utilização, a importação, a exportação, o destino final dos resíduos e embalagens, o registro, a classificação, o controle, a inspeção e a fiscalização de agrotóxicos, seus componentes e afins, e dá outras providências.". Disponível em: <http://www.planalto.gov.br/ ccivil_03/leis/l7802.htm>. Acesso em: 19 jan. 2014.
} 
planejada no meio ambiente, dentre outras, são normas específicas da CTNBio publicadas por esta na forma de Instruções Normativas. ${ }^{(47)}$

Em 2003, em meio à revolta popular e dos ambientalistas, em decorrência da inconstitucionalidade das Medidas Provisórias 113 e 131 referentes ao plantio de soja transgênica realizado de forma ilegal na região sul do país, é publicado o Decreto da Rotulagem (Decreto $\left.n^{\circ} 4.680\right) .^{(48),(49)}$ Este regulamenta a rotulagem com base no Código de Defesa do Consumidor, que exige o direito básico de informação ao consumidor a respeito dos produtos, além de exigir informações sobre a possibilidade de o produto comercializado oferecer algum risco à saúde do indivíduo. $\mathrm{O}$ decreto estabelece que qualquer produto que possua em sua composição mais de $1 \%$ (que é a quantidade mínima mensurável da nova proteína) de OGM ou seus derivados deverá apresentar rotulagem específica completa, identificando o produto geneticamente modificado e sua origem de forma detalhada, incluindo informações sobre espécies e vetores utilizados. Algo semelhante ocorre na União Europeia e na Austrália e Nova Zelândia, ao passo que o Japão parece ser mais permissivo, já que o limite que obriga a rotulagem é de $5 \%$ para a soja. ${ }^{(50)}$ Dessa forma, tenta-se impedir que produtores misturem os alimentos geneticamente modificados em seus produtos, sem oferecer essa informação aos consumidores, e permite a escolha de produtos livres de OGMs. ${ }^{(51),(52)}$ Outra vantagem que a rotulagem oferece é rastreabilidade no caso da ocorrência de problemas com os alimentos geneticamente modificados, ou seja, a rotulagem auxilia a biovigilância. ${ }^{(53)}$ O símbolo estabelecido para identificação dos OGMs foi um triângulo com fundo amarelo, o qual foi implementado pela portaria do Ministério da Justiça $n .^{\circ} 2.658 / 03$.

A necessidade da devida rotulagem dos produtos contendo OGMs foi demonstrada no trabalho de Schnettler et al, ${ }^{(54)}$ que realizaram uma pesquisa com 800 consumidores a respeito de suas preferências com relação aos alimentos geneticamente modificados, em duas cidades do Chile. Após submeter os resultados à conjoint analysis, os autores verificaram que tanto a preferência por alimentos que não continham OGMs quanto a rejeição por produtos geneticamente modificados foram mais ocorrentes no caso de alimentos oriundos de produtos vegetais, mostrando que existe uma preferência entre diferentes produtos e

\footnotetext{
${ }^{47}$ BRASIL. Lei $n^{\circ} 7.802$, de 11 de julho de 1989, cit.

${ }^{48}$ BRASIL. Decreto $n^{\circ} 4.680$, de 24 de abril de 2003. "Regulamenta o direito à informação, assegurado pela Lei $n^{\circ} 8.078$, de 11 de setembro de 1990, quanto aos alimentos e ingredientes alimentares destinados ao consumo humano ou animal que contenham ou sejam produzidos a partir de organismos geneticamente modificados, sem prejuízo do cumprimento das demais normas aplicáveis.". Disponível em: <http://www.planalto.gov.br/ccivil_03/decreto/2003/d4680.htm>. Acesso em: 19 jan. 2014.

${ }^{49}$ Id. Ibid., p. 5.

${ }^{50}$ Id. Ibid., p. 18.

${ }^{51}$ Id. Ibid., p. 38.

${ }^{52}$ Id. Ibid., p. 25.

${ }^{53}$ Id., loc. cit.

${ }^{54}$ SCHNETTLER, Berta; MIRANDA, Horácio; SEPÚLVEDA, José; DENEGRI, Marianela. Preferência dos consumidores aos alimentos geneticamente modificados de origem animal e vegetal no Chile. Ciência e Tecnologia dos Alimentos, Campinas, v. 32, n.1, p. 15-25, 2012.
} 
que, muitas vezes, essa preferência torna-se mais relevante que seu custo. Isso implica a grande necessidade de se garantir o direito de escolha, o que impõe uma postura mais exigente e fiscalizadora dos órgãos públicos.

A nova Lei de Biossegurança foi publicada em 2005 (Lei $n^{\circ} 11.105$ ) e apresenta algumas alterações na regulamentação acerca dos OGMs. A nova lei ratifica a existência da CTNBio e complementa suas competências, além de também criar o Conselho Nacional de Biossegurança (CNBS), que possui responsabilidade pela aplicação das políticas ambientais relacionadas à temática da biosseguridade dos OGMs, dentre outras questões. Dessa forma, o CNBS, como órgão autônomo, atua nos casos que envolvem a qualidade de vida, a saúde da população e a preservação do meio ambiente que tenham suas origens em causas distintas dos OGMs, complementando as ações no campo da biossegurança no país. A nova lei também origina o Sistema de Informação de Biossegurança (SIB), que deve ser sustentado e atualizado por todos os órgãos que atuam com OGMs, oferecendo informações completas sobre os produtos e projetos relacionados à biotecnologia e biossegurança no Brasil.

O desenvolvimento de produtos geneticamente modificados deve ser monitorado de forma detalhada pela CTNBio e pelos órgãos fiscalizadores (ministérios relacionados às diversas questões afeitas aos OGMs). O controle de todas as etapas da pesquisa à liberação comercial e ao consumo humano de transgênicos é uma das principais ações de vigilância relativa aos OGMs, incluindo sua fiscalização. Trata-se de um ciclo de etapas que envolvem avaliação e monitoramento da empresa e do produto a ser desenvolvido, por parte dos respectivos órgãos de fiscalização e, principalmente, pela CTNBio, que é considerada a máxima instância em relação aos OGMs. ${ }^{(55)}$ Dessa forma, o primeiro passo para iniciar uma pesquisa com OGM é o registro da empresa na CTNBio para obtenção do Certificado de Qualidade em Biossegurança (CQB), sendo exigidos como requisitos mínimos sua inscrição como pessoa jurídica dotada de idoneidade financeira, a criação de uma Comissão Interna de Biossegurança (CIBio), a descrição da finalidade a que se propõe a atividade a ser desenvolvida, bem como a classificação do produto, a relação dos organismos que serão manipulados, dentre outras informações a respeito da empresa. ${ }^{(56)}$

Em seguida, é necessário obter autorização para desenvolvimento de pesquisa com OGMs nos respectivos órgãos fiscalizadores, como o MAPA, no caso de produtos de origem vegetal. A partir desse momento, iniciam-se os procedimentos para obtenção do registro e liberação para desenvolver atividades de pesquisa em áreas confinadas (laboratórios e estufas) por parte do Ministério do Meio Ambiente. No caso específico dos produtos com finalidade biopesticida, também é necessário obter o RET/OGM de fase I regulamentado pelo MAPA, Ministério

\footnotetext{
${ }^{55}$ AMÂNCIO, Mônica Cibele. Aspectos legais da pesquisa com transgênicos no Brasil. In: FALEIRO, Fábio Gelape; ANDRADE, Solange Rocha M. de. Biotecnologia, transgênicos e biossegurança. Planaltina: Embrapa Cerrados, 2009. p. 79-108.

${ }^{56}$ Id. Ibid., p. 35.
} 
do Meio Ambiente e Anvisa. ${ }^{(57)}$ A conclusão da pesquisa em área confinada deve ser avaliada pela CTNBio para emissão do parecer técnico prévio conclusivo sobre a liberação planejada do OGM no meio ambiente. Uma vez liberada a pesquisa em campo pela CTNBio, as atividades de plantio serão iniciadas com a obtenção da Autorização Temporária de Experimento de Campo (ATEC) pelo MAPA e da Licença de Operação para Área de Pesquisa (LOAP) pelo MMA, que já avaliam os riscos e o impacto da liberação do produto transgênico no ambiente. ${ }^{(58)}$ Os produtos biopesticidas necessitam novamente da obtenção do RET/OGM, agora de acordo com a área plantada.

Para a liberação comercial dos produtos geneticamente modificados é necessário adquirir as licenças ambientais para liberação pré-comercial e comercial pelo Ministério do Meio Ambiente. Nesse momento, os estudos e relatórios de impacto ambiental são essenciais para avaliação do OGM e para o planejamento de sua liberação para plantio comercial no país, que em teoria requer análise de macrozoneamento por espécie do Brasil(59) (no entanto, até o momento a CTNBio não exigiu para nenhum cultivar a realização do EIA/RIMA). Também é necessária a Avaliação da Segurança dos produtos geneticamente modificados destinados ao consumo humano, por parte da ANVISA. Finalmente, deve haver a aprovação da CTNBio para comercialização do OGM, que será, então, registrado no respectivo órgão fiscalizador. Mesmo após a aprovação para o comércio, faz-se necessário um monitoramento caso a caso, visto que cada produto geneticamente modificado, separadamente, é uma inovação.

Estudos científicos são frequentemente usados para apoiar as decisões políticas relacionadas aos transgênicos. Antes da liberação comercial, os produtos transgênicos são submetidos a uma avaliação de risco para garantir que eles não causem efeitos prejudiciais inaceitáveis. No caso de variedades transgênicas resistentes a insetos, um foco da avaliação de risco é o potencial impacto negativo sobre insetos não alvos. Dentro desse contexto, Álvarez-Alfageme et al. ${ }^{(6)}$ mostraram estudos de toxicidade em laboratório com Cry1Ab e Cry3Bb1 na Suíça. Esses autores mostraram que essas duas proteínas Cry, mais comumente expressas em variedades de milho $B t$, não causam efeito adverso em larvas de joaninha-de-duas-manchas (Adalia bipunctata).

A dualidade de posicionamento em relação aos OGMs, entre EUA e União Europeia, se expandiu para vários países produtores de matérias-primas, como a Argentina e o Brasil, de tal forma que estes tendem a seguir os padrões internacionais de boas condutas relacionadas aos OGMs, com legislações

\footnotetext{
${ }^{57}$ AMÂNCIO, Mônica Cibele. op. cit., p. 46.

${ }^{58}$ Id. Ibid., p. 16

${ }^{59}$ Id. Ibid., p. 36.

${ }^{60}$ ÁLVAREZ-ALFAGEME, Fernando; BIGLER, Franz; ROMEIS, Jorg. Laboratory toxicity studies demonstrate no adverse effects of Cry1 $\mathrm{Ab}$ and $\mathrm{Cry3Bb} 1$ to larvae of Adalia bipunctata (Coleoptera: Coccinellidae): the importance of study design. Transgenic Research, Zurique, v. 20, n. 3, p.467479, 2011.
} 
protetoras, fundamentadas no Princípio da Precaução, e com normatização de agências controladoras e fiscalizadoras das atividades com produtos geneticamente modificados, visando preservar o ambiente e a saúde humana e animal. Um exemplo dessa tentativa em seguir normas rígidas em relação aos OGMs no Brasil é a Instrução Normativa $n^{\circ} 20$, que apresenta diversas questões que devem ser respondidas pelos proponentes do produto e um fluxograma que estabelece os procedimentos de avaliação da segurança alimentar. Essas questões versam sobre diferentes itens do novo produto (como, por exemplo, as características do organismo doador e seu potencial de alergenicidade), o que mostra o cuidado que a CTNBio procura ter ao aprovar um alimento geneticamente modificado. ${ }^{(61)}$ Entretanto, atualmente prevalece um posicionamento liberal, por parte das próprias agências controladoras, resultando em liberações de OGMs que não seguem todos os cuidados previstos nas leis. ${ }^{(62)}$ No Brasil, isso ocorre claramente desde 2007. Entretanto, desde a primeira liberação comercial de OGM no país, realizada em 1998 com a soja transgênica, já se discutia a sua inconstitucionalidade pelo fato de não se exigir Estudo e Relatório de Impacto Ambiental. A tendência liberal da CTNBio, considerada como propulsora do desenvolvimento técnico e científico na área da biotecnologia, ainda gera muita polêmica em relação à seguridade ambiental e à predominância da produção de transgênicos no país. Alguns autores consideram essa expansão liberal uma tentativa dos EUA de diminuir o comércio internacional de produtos não transgênicos e, consequentemente, alcançar a dominância no mercado de matérias-primas, já que é o país que mais produz OGMs no mundo. ${ }^{63)}$

\section{Considerações finais}

A produção de alimentos transgênicos já foi adotada tanto por países desenvolvidos como em desenvolvimento, incluindo nestes os pequenos agricultores, os quais atualmente representam uma importante parcela dos produtores destes alimentos. Isso demonstra claramente a independência desse tipo de tecnologia em relação a recursos econômicos. No Brasil, a área de cultivo de OGMs vem aumentando anualmente, de modo que o espaço existente entre a produção brasileira e a liderança americana vem diminuindo.

Entretanto, uma política de implantação e fiscalização desses produtos ainda não está bem estabelecida, mesmo sendo algo relevante, visto que os resultados em relação aos novos genes gerados não são previsíveis.

A regulamentação brasileira relativa à biossegurança dos produtos geneticamente modificados é muito ampla, capilarizando-se em diversos órgãos (CTNBio - de maior instância -, MAPA, Sisnama, Anvisa), responsáveis por diferentes

\footnotetext{
${ }^{61}$ ÁLVAREZ-ALFAGEME, Fernando; BIGLER, Franz; ROMEIS, Jorg. Laboratory. op. cit., p. 18.

${ }^{62}$ Id. Ibid., p. 5.

${ }^{63}$ Id. Ibid., p. 19.
} 
funções. Isso apresenta vantagens e desvantagens. Por um lado, a divisão de funções não sobrecarrega nenhum órgão, visto que cada um é responsável por parte do processo. Por outro lado, torna o processo complexo e burocrático, muitas vezes dificultando-o.

As instâncias governamentais deveriam assegurar a completa análise dos projetos de OGMs pesquisados e comercializados, a fim de defender a integridade do meio ambiente e da saúde humana e animal. Desde sua criação, a CTNBio não foi capaz de propor a Política Nacional de Biossegurança, estipulada na Lei $n^{\circ} 11.105 / 05$. Além disso, desde o início de sua existência, tampouco foram estabelecidos critérios mínimos para a avaliação das solicitações de liberação ambiental dos OGMs, tais como as dimensões consideradas aceitáveis para uma área experimental.

Outro fator importante refere-se à ausência de critérios para as liberações experimentais no meio ambiente por parte da CTNBio. De acordo com Marinho \& Minayo-Gomez, ${ }^{64)}$ já foram liberadas, sem demais estudos e relatórios, áreas de até 110 hectares para experimentação de produtos transgênicos, fato que fere claramente a legislação brasileira que preconiza o princípio da precaução. Além disso, embora a Lei de Biossegurança tenha sido aprimorada em 2005, ainda prevalecem contradições, como o fato de não ser expresso no texto o princípio da precaução e a persistência da não obrigatoriedade de realização do EIA e RIMA para aprovação de OGMs.

A omissão dos órgãos de vigilância e fiscalização também poderá contribuir para os eventuais danos ao meio ambiente e à saúde de consumidores. Em 2004, o então diretor da Anvisa declarou que a rotulagem dos produtos que contenham mais de $1 \%$ de transgênicos não se mostra útil do ponto de vista da saúde e não auxilia a fiscalização, sendo necessária intensa análise laboratorial para detecção e diferenciação dos produtos transgênicos dos convencionais. Este ainda afirmou: "Não esperem que a vigilância colete produtos nos supermercados para fazer tais análises. Não é nossa prioridade". ${ }^{65)}$ De fato, a detecção e o rastreamento de transgênicos em alimentos não é um procedimento simples. Existem diversas metodologias com diferentes vantagens e limitações. Em alimentos processados, a detecção de traços de OGMs deve ser feita com base em análise de DNA, o que exige presença de pessoal treinado e equipamentos especiais, além do alto custo requerido. No entanto, a maioria dos OGMs cujo uso é permitido na alimentação possui sequências comuns, o que torna possível a sua triagem pelo método PCR (Polymerase Chain Reaction). Mesmo com a existência de técnicas que permitem a identificação de OGMs em alimentos e

\footnotetext{
${ }^{64}$ MARINHO, Carmem L. C.; MINAYO-GOMEZ, Carlos. Decisões conflitivas na liberação dos transgênicos no Brasil. São Paulo em Perspectiva, São Paulo, v.18, n.3, p. 96-102, 2004.

${ }^{65}$ ANVISA diz que é difícil fiscalizar transgênicos. 2004. O Estado de S. Paulo, São Paulo. Disponível em: <http://www.institutocarbonobrasil.org.br/noticias6/noticia=111772>. Acesso em: 19 maio 2011.
} 
a exigência de rotulagem, encontram-se produtos irregulares em prateleiras de estabelecimentos alimentícios.

Nos últimos anos, a Anvisa mostrou-se mais atuante na elaboração de normativas de monitoramento do comércio de OGMs no país. No entanto, esse envolvimento permanece meramente político, sendo pouco efetiva a participação direta da Agência em ações de fiscalização e apreensão de produtos transgênicos. Esse fato se confirma quando considerada a identificação de irregularidades de rótulos de produtos alimentícios, de importantes marcas, no início de 2011. As irregularidades foram detectadas pelo Departamento de Proteção e Defesa do Consumidor em parceria com o PROCON de diversos Estados do país, não sendo citada a participação da Anvisa no processo de fiscalização. ${ }^{(66)}$ Portanto, sendo o MS e o MAPA os órgãos responsáveis pelo controle de toda a cadeia alimentar, a fiscalização realizada por eles ainda é precária. Essa precariedade na fiscalização contrasta com a real importância de se assegurar o direito dos cidadãos, determinado pelo Código de Defesa do Consumidor.

Por seu caráter mais cauteloso, a legislação europeia é descrita como conservadora e até mesmo contrária ao desenvolvimento técnico-científico. No entanto, trata-se das normativas mais completas relativas aos OGMs. De forma geral, todas as organizações envolvidas se certificam da aprovação legal do produto e que este não seja nocivo para a saúde humana, animal e ambiental. O caráter conservador das normativas se encontra na rigorosa exigência de estudos de impacto ambiental para a avaliação de segurança dos produtos geneticamente modificados e em sua rastreabilidade, que auxilia na rotulação dos OGMs comercializados.

Os EUA apresentam uma postura de dominação do mercado, seja para consumo interno, seja externo, e sua tendência liberal está se difundindo para outros países produtores de OGMs por conta de pressão comercial, gerando maiores preocupações com os potenciais ou efetivos impactos ambientais ocasionados pelo aumento do plantio e circulação de transgênicos. A fidelidade ao princípio da equivalência substancial implica a não exigência da segregação e rotulagem de alimentos geneticamente modificados pelas normas americanas. No Brasil, por sua vez, considerando que a rotulagem de transgênicos é obrigatória, a falta de informação a respeito da presença de OGMs dificulta a atuação das instâncias que fiscalizam os produtos importados. Desse modo, a escolha entre adquirir ou não um produto contendo traços de OGMs por parte do consumidor não é possibilitada, ferindo seus direitos.

Assim, mesmo com uma legislação abrangente, o Brasil ainda apresenta graves problemas com a regulamentação de OGMs, seja por falhas na edição e revisão

\footnotetext{
${ }^{66}$ NESTLÉ e Kraft serão processadas por rótulos em transgênicos. 2011. Folha de S. Paulo, São Paulo. Disponível em: <http://www1.folha.uol.com.br/mercado/889529-nestle-e-kraft-seraoprocessadaspor-rotulos-em-transgenicos.shtml>. Acesso em: 30 abr. 2011.
} 
das respectivas normativas, seja por falhas dos órgãos responsáveis pela vigilância e fiscalização dos produtos transgênicos. Os desafios permanecem em assegurar a exigência de estudos de impacto ambiental dos OGMs, e monitorar e fiscalizar os produtos plantados e comercializados, para proteger o ambiente e a saúde da população.

\section{Referências}

ÁLVAREZ-ALFAGEME, Fernando; BIGLER, Franz; ROMEIS, Jorg. Laboratory toxicity studies demonstrate no adverse effects of Cry1 Ab and Cry3Bb1 to larvae of Adalia bipunctata (Coleoptera: Coccinellidae): the importance of study design. Transgenic Research, Zurique, v. 20, n. 3, p.467-479, 2011.

AMÂNCIO, Mônica Cibele. Aspectos legais da pesquisa com transgênicos no Brasil. In: FALEIRO, Fábio Gelape; ANDRADE, Solange Rocha M. de. Biotecnologia, transgênicos e biossegurança. Planaltina: Embrapa Cerrados, 2009. p. 79-108.

; SAMPAIO, Maria José. Legislação de biossegurança no Brasil: cenário atual. Conselho de Informações de Biotecnologia, 2004. Disponível em: <http:// cib.org.br/wp-content/uploads/ 2011/10/legislacao_biosseguranca_brasil_ monica_cibele.pdf>. Acesso em: 10 maio 2011.

ANVISA diz que é difícil fiscalizar transgênicos. 2004. O Estado de S. Paulo. Disponível em: <http://www.institutocarbonobrasil.org.br/noticias6/noticia= 111772>. Acesso em: 19 maio 2011.

CAMARA, Maria Clara Coelho; MARINHO, Carmem L. C.; GUILAM, Maria Cristina Rodrigues; NODARI, Rubens Onofre. Transgênicos: avaliação da possível (in)segurança alimentar através da produção científica. História, Ciências, Saúde-Manguinhos, Rio de Janeiro, v. 16, n. 3, p. 669-681, 2009.

COELHO, Marcus Vinícius S. Medidas e ações envolvendo OGM e seus derivados no âmbito das competências do MAPA. Reunião GT - Transgênico da $3^{\mathrm{a}}$ e $4^{\mathrm{a}}$ CCR. SDA/MAPA. Brasília, 17 de setembro de 2007.

COSTA, Joselaine da ; KIST, Ataídes.; MATTÉ, Glavur Rogério; MATTÉ, Maria Helena. Alimentos geneticamente modificados: aspectos regulatórios e de saúde pública. Revista de Direito Sanitário, São Paulo, v. 4, n. 3, p. 107-125, 2003.

CTNBIO, 2011. Eventos aprovados pela CTNbio. Disponível em: <http://www. cib.org.br/biotecnologia/regulamentacao/ctnbio/eventos-provados>. Acesso em: 21 abr. 2011.

EDUARDO, Maria Bernadete de Paula; MIRANDA, Isaura Cristina Soares de. Programas de Vigilância Sanitária. In: Noções básicas sobre vigilância sanitária. São Paulo: Fundação Peirópolis, 1998. v. 8. 
FAO/WHO. Evaluation of allergenicity modified foods: report of a Joint FAO/ WHO Expert Consultation on Allergenicity of Foods Derived from Biotecnology. 2000. Disponível em: <http://www.fao.org/docrep/007/ y0820e/y0820e00.htm>. Acesso em: 8 ago. 2011.

FARIA, Carmen Rachel S. M. A polêmica dos transgênicos: aspectos técnicos, legais e econômicos. Senado Federal - Consultoria Legislativa, Brasília, 31 p. 2005. Disponível em: <http://www.senado.gov.br/senado/conleg/artigos/ politicasocial/ApolemicadosTransgenicos.pdf>. Acesso em: 03 abr. 2011.

GMO-Compass. EU: GMO Authorisation Procedures. 10 Jan. 2006. Disponível em: <http://www.gmocompass.org/eng/regulation/regulatory_process/157. eu_gmo_authorisation_procedures.html>. Acesso em: 12 maio 2011.

The European Regulatory System. Genetic Engineering, Plants, and Food. 2, Jun., 2006. Disponível em: <http://www.gmo-compass.org/eng/ regulation/regulatory_process/156.european_regulatory_system_genetic_ engineering.html>. Acesso em: 11 maio 2011.

JAMES, Clive. Situação Global das Culturas Biotecnológicas/ GM Comercializadas: 2008. In: RELATÓRIO do Serviço Internacional para a Aquisição de Aplicações de Agrobiotecnologias (ISAAA), 2008. Sumário Executivo, n. 39, 31p. Disponível em: <http://www.isaaa.org/resources/publicacations/briefs/39 /default.html>. Acesso em: 21 abr. 2011.

Situação Global das Culturas Biotecnológicas/ GM Comercializadas: 2009. In: RELATÓRIO do Serviço Internacional para a Aquisição de Aplicações de Agrobiotecnologias (ISAAA), 2009. Sumário Executivo, n. 41, 50p. Disponível em: <http://www.isaaa.org/resources/publicacations/briefs/ 41/default.html>. Acesso em: 21 abr. 2011.

Situação Global das Lavouras GM Comercializadas: 2011. In: RELATÓRIO do Serviço Internacional para a Aquisição de Aplicações de Agrobiotecnologias (ISAAA), 2011. Sumário Executivo, n. 43, 36p. Disponível em: <http://www.isaaa.org/resources/publicacations/briefs/43/default.html>. Acesso em: 23 ago. 2011.

KUIPER, Harry A.; KLETER, Gijs A.; NOTEBORN, Hub P. J. M.; KOK, Esther J. Assessment of the food safety issues related to genetically modified foods. The Plant Journal, London, v.27, n.6, p.503-528, 2001.

LAJOLO, Franco Maria; NUTTI, Marília Regini. Transgênicos: bases científicas da sua segurança. São Paulo: Sociedade Brasileira de Alimentação e Nutrição, 2003. $112 \mathrm{p}$.

LEITE, Marcelo. EUA podem rever liberalismo transgênico. Folha de $S$. Paulo, São Paulo, 12 jan. 2011. Disponível em: <http://www.agrosoft.org.br/ agropag/217104.htm>. Acesso em: 12 maio 2011. 
MARINHO, Carmem L. C.; MINAYO-GOMEZ, Carlos. Decisões conflitivas na liberação dos transgênicos no Brasil. São Paulo em Perspectiva, São Paulo, v.18, n.3, p. 96-102, 2004.

MILÉRIO, Júnior. Brasil bate recorde em biotecnologia agrícola em 2011: área plantada com transgênicos subiu $20 \%$ e País aprovou primeira semente nacional. Sou Agro, 7 fev. 2012. Disponível em: <http://www.souagro.com.br/brasil-baterecorde-em-biotecnologia-agricola>. Acesso em: 23 ago., 2012.

MILLSTONE, Erik; BRUNNER, Eric; MAYERS, Sue. Beyond substancial equivalence. Nature, v. 401, p.525-526, 1999.

MONSANTO do Brasil Ltda. Biotecnologia: soluções para o mundo de amanhã. nov. 1997.

NESTLÉ e Kraft serão processadas por rótulos em transgênicos. 2011. Folha de S. Paulo. Disponível em: <http://www1.folha.uol.com.br/mercado/889529nestle-e-kraft-seraoprocessadas-por-rotulos-em-transgenicos.shtml>. Acesso em: 30 abr. 2011.

PUSZTAI, ÀRPÁD. Pusztai's submission on the health impact of GM crops - Evidence to the Health committee of the Scottish Parliament. 4 dez. 2002. Disponível em: <http://ngin.tripod.com/041202e.htm>. Acesso em: 12 ago. 2011.

RODRIGUES, Regina S. Minazzi. Alimentos transgênicos. In: Higiene e vigilância sanitária de alimentos. 2. ed. São Paulo: Varela Ed.; Livr., 2003. p. 541-573.

SCHNETTLER, Berta; MIRANDA, Horácio; SEPÚLVEDA, José; DENEGRI, Marianela. Preferência dos consumidores aos alimentos geneticamente modificados de origem animal e vegetal no Chile. Ciência e Tecnologia dos Alimentos, Campinas, v. 32, n.1, p. 15-25, 2012.

SUZUKI, Jorge Brunetti. OGM: aspectos polêmicos e a nova lei de biossegurança. Jus Navigandi, Teresina, n. 997. Disponível em: <http:/jus.uol.com.br/revista/ texto/8148/ogm-aspectos-polemicos-e-a-nova-lei-de-biosseguranca>. Acesso em: 28 abr. 2011. 